\title{
PELATIHAN PIJAT OKSITOSIN PADA KELUARGA IBU NIFAS DI RSUP dr. SOERADJI TIRTONEGORO KLATEN
}

\author{
Paryono \\ Kementerian Kesehatan Politeknik Kesehatan Surakarta Jurusan Kebidanan
}

\begin{abstract}
Training Of Oxytocin Massage, Postpartum Family. Training is a a shortterm investment to help improve a person's ability to perform his/ her duties. The oxytocin massage can be done by the nearest person or post partum family. Tthe lack knowledge on postpartum family about oxytocin massage causes the need for information about the oxytocin massage. In order for information about oxytocin massage is more easily delivered then the business of oxytocin massage training to the post partum family. If the postpartum family can do the oxytocin massage, the milk production (ASI) becomes smooth and the baby gets enough breast milk. Goal this research was to know the difference of oxytocin massage skills before and after being trained in the postpartum family in dr. Soeradji Tirtonegoro Klaten hospital. The research type is quasi experiment with one group pretest-posttest research design. The population in this study is the postpartum family in Melati I room dr. Soeradji Tirtonegoro Klaten hospital. Samples taken are the postpartum families who was given the training of oxytocin massage is 30 people. Data collection was done by intervening in oxytocin massage training and observation. Data were analyzed univariant with central tendency and bivariant analysis with Paired Sample t-test. Univariant analysis showed that the average score of oxytocin massage skills in the postpartum family before training $2.2+4.65$ and the average score of oxytocin massage skills in the postpartum family after receiving training $16.6+0.49$. The bivariant analysis shows that the value of $t$ test $-17.124(-17.124>-2.045<2.045)$. It proves that Ho is rejected and Ha accepted which means there is a difference in oxytocin massage skills before and after being trained in the postpartum family in dr. Soeradji Tirtonegoro Klaten hospital.
\end{abstract}

Keywords: Oxytocin Massage, Training, Skills

Abstrak: Pelatihan Pijat Oksitosin, Keluarga Ibu Nifas. Pelatihan merupakan suatu bentuk investasi jangka pendek untuk membantu meningkatkan kemampuan seseorang dalam melaksanakan tugasnya. Pijat oksitosin dapat dilakukan dengan bantuan orang terdekat ibu nifas atau keluarga dari ibu nifas. Namun kurangnya pengetahuan keluarga dari ibu nifas tentang pijat oksitosin menyebabkan perlunya informasi tentang pijat oksitosin kepada keluarga dari ibu nifas. Agar informasi tentang pijat oksitosin lebih mudah disampaikan maka dilakukan usaha pelatihan pijat oksitosin kepada keluarga ibu nifas. Jikalau keluarga ibu nifas dapat melakukan pijat oksitosin, maka produksi Air Susu Ibu (ASI) menjadi lancar dan bayi cukup mendapatkan makanan ASI. Tujuan penelitian untuk mengetahui perbedaan ketrampilan pijat oksitosin sebelum dan sesudah diberi pelatihan pada keluarga ibu nifas di RSUP dr. Soeradji Tirtonegoro Klaten. Jenis penelitian adalah quasi experiment dengan rancangan penelitian one group 
pretest posttest. Populasi dalam penelitian ini adalah keluarga dari ibu nifas yang dirawat di bangsal Melati I RSUP dr. Soeradji Tirtonegoro Klaten. Sampel yang diambil adalah keluarga dari ibu nifas yang dirawat di ruang Melati RSUP dr. Soeradji Tirtonegoro Klaten yang diberi pelatihan pijat oksitosin sebanyak 30 orang. Pengumpulan data dilakukan dengan melakukan intervensi pelatihan pijat oksitosin dan observasi. Data dianalisis univariant dengan tendensi sentral dan analisis bivariant dengan uji Paired Sample t-test. Analisis univariant menunjukkan bahwa skor rerata ketrampilan pijat oksitosin pada keluarga ibu nifas sebelum mendapat pelatihan $2,2 \pm$ 4,65 dan skor rerata ketrampilan pijat oksitosin pada keluarga ibu nifas setelah mendapat pelatihan $16,6 \pm 0,49$. Analisis bivariant menunjukkan bahwa nilai $t$ test $17,124(-17.124>-2.045<2.045)$. Hal tersebut membuktikan bahwa Ho ditolak dan Ha diterima yang artinya terdapat perbedaan yang positif pada ketrampilan pijat oksitosin sebelum dan sesudah diberi pelatihan pada keluarga ibu nifas di RSUP dr. Soeradji Tirtonegoro Klaten.

Kata Kunci : Pijat Oksitosin, Pelatihan, Ketrampilan

\section{PENDAHULUAN}

Air Susu Ibu (ASI) merupakan makanan terbaik bagi bayi baru lahir ${ }^{10)}$. Menyusui adalah suatu proses alamiah karena menyusui memberi banyak keuntungan mulai dari nutrisi, imunologi dan psikologis. Proses lakstasi dikelompokkan menjadi lima yaitu laktogenesis, produksi susu, ejeksi susu, kolostrum dan susu ibu, sedangkan reflek menyusui pada ibu terbagi menjadi tiga yaitu reflek prolaktin, reflek ereksi puting susu dan reflek let down. Produksi ASI dipengaruhi oleh faktor langsung yang meliputi hormon prolaktin, perilaku menyusui, faktor fisiologi, faktor psikologi, faktor lain yaitu teknik memerah ASI dan memijat payudara dan pijat oksitosin, sedangkan faktor tidak langsung meliputi pembatasan waktu ibu menyusui, faktor sosial budaya, paritas, umur, faktor kenyamanan ibu dan faktor bayi.

ASI sebagai makanan terbaik bagi bayi perlu diperhatikan faktor-faktor yang mempengaruhinya. Untuk melancarkan produksi ASI dilakukan usaha untuk merangsang hormon prolaktin dan oksitosin dengan melakukan perawatan yakni melalui pijat oksitosin. Pijat oksitosin dapat dilakukan dengan bantuan orang terdekat ibu nifas atau keluarga. Ketidaktahuan keluarga tentang pijat oksitosin menyebabkan keluarga tidak bisa berperan dalam upaya meningkatkan produksi dan lancarnya laktasi.

Pijat oksitosin merupakan upaya merawat sedini mungkin payudara ibu untuk mempersiapkan payudara sebagai penghasil ASI dengan menstimulasi refleks oksitosin melalui pemijatan tulang belakang bagian atas kearah bawah sampai pinggang dan diakhiri kearah luar sampai batas di bawah payudara. Pijat oksitosin bermanfaat untuk mencegah resiko pembengkakan payudara, mengurangi sumbatan ASI, merangsang pelepasan hormon oksitosin, dan mempertahankan produksi ASI ketika ibu dan bayi sakit. Secara fisiologis, pemijatan pada medula spinalis yang merupakan bagian dari susunan saraf pusat yang dikelilingi tulang belakang dapat merangsang produksi oksitosin oleh 
kelenjar hipofisis posterior. Oksitosin akan masuk ke dalam aliran darah dan menyebabkan kontraksi sel-sel mioepitel yang mengelilingi alveolus mamae dan duktus laktiferus. Kontraksi sel-sel mioepitel ini mendorong ASI keluar dari alveolus melalui duktus laktiferus menuju sinus laktiferus, di tempat inilah ASI disimpan.

Agar informasi tentang pijat oksitosin lebih mudah disampaikan maka dilakukan usaha pelatihan pijat oksitosin kepada keluarga ibu nifas. Pelatihan adalah suatu bentuk investasi jangka pendek untuk membantu meningkatkan kemampuan seseorang dalam melaksanakan tugasnya. Tujuan pelatihan adalah meningkatkan kualitas dan kemampuan keluarga ibu nifas dalam turut serta mempersiapkan ASI yang cukup sebagai makanan terbaik bagi bayinya $^{2)}$. Melalui pelatihan seseorang dapat meningkatkan pengetahuan, sikap dan keterampilan, sehingga mampu meningkatkan kompetensi yang diharapkan.

Pelatihan dianggap penting untuk keluarga ibu nifas karena bertujuan meningkatkan pengetahuan, ketrampilan dan sikap keluarga ibu nifas dalam mencukupi kebutuhan laktasi. Dengan pelatihan pijat oksitosin pada keluarga ibu nifas, maka keluarga dapat melakukan pijat oksitosin pada ibu nifas sera mandiri sehingga membantu merangsang pelepasan hormon oksitosin yang akan memacu produksi ASI (Rusli, 2005)

\section{METODE PENELITIAN}

Penelitian ini bersifat deskriptif analitik dengan metode quasi-experiment atau eksperimen semu dan rancangan penelitian one group pretest posttest.
Rancangan dari penelitian yang akan dilakukan adalah sebagai berikut :

\begin{tabular}{|ccc|}
\hline Pretest & Perlakuan & Posttest \\
\hline 01 & $\mathrm{X}$ & 02 \\
\hline
\end{tabular}

Keterangan :

01 : Observasi sebelum

$\mathrm{X}$ : Diberikan pelatihan pijat oksitosin

02 : Observasi setelah pelatihan

Populasi dalam penelitian ini adalah keluarga dari ibu nifas yang dirawat di ruang Melati RSUP dr. Soeradji Tirtonegoro Klaten dengan jumlah pasien ibu nifas 120 orang per bulan. Pengambilan sampel menggunakan teknik non random sampling yakni quota sampling. Alasan peneliti menggunakan teknik sampling ini karena anggota keluarga yang menunggu pasien tidak selalu sama. Kriteria inklusi meliputi: menunggu pasien, tinggal satu rumah dengan ibu nifas dan komunikatif.

Variabel Penelitian meliputi variabel bebas yaitu pelatihan pijat oksitosin, sedangkan variabel terikat yaitu ketrampilan pijat oksitosin sebelum pelatihan dan setelah pelatihan.

Instrumen yang digunakan penelitian ini adalah checklist pijat oksitosin terdiri atas 17 pernyataaan. Pengujian validitas dengan validitas isi/konten yang sudah dikonsultasikan kepada ahli dan dinyatakan valid, Sedang uji reliabilitas dilakukan dengan test-retest yang dianalisis dengan korelasi product moment dengan hasil 0,76 sehingga dinyatakan reliabel.

Pengolahan data dilakukan dengan tahap editing, coding, data entry dan tabulating. Analisis atas hipotesis yang digunakan adalah analisis univariant yaitu tendensi sentral (mean, median, mode dan standar deviasi) serta bivariant untuk menguji hipotesis: Ada perbedaan ketrampilan pijat oksitosin sebelum dan sesudah diberi pelatihan pada keluarga ibu 
nifas di RSUP dr. Soeradji Tirtonegoro Klaten dengan uji beda t-test berpasangan (Paired Sample t-test) pada alpha 0,01.

\section{HASIL PENELITIAN}

Hasil analisis univariant menunjukkan bahwa skor ketrampilan pijat oksitosin pada keluarga ibu nifas sebelum mendapat pelatihan dengan rerata $2,2 \pm 4,65$. setelah mendapat pelatihan $16,6 \pm 0,49$. Hasil analisis bivariant dengan melakukan uji Paired Sample t-test berpasanagan dengan hasil $t_{\text {hitung }}$ 17,124 dengan signifikasi 0,01. Jika dikonsultasikan dengan tabel $\mathrm{t}$ maka didapatkan: $t_{\text {tabel }}$ 2,045. Hasil di atas menunjukkan $-17.124>-2.045<2.045$ sehingga Ho ditolak dan Ha diterima. Jika dilihat dari nilai probabilitas didapatkan $\mathrm{p}$ value 0,001 ( $\mathrm{p}<0,01)$. Hasil diatas menunjukkan ada perbedaan ketrampilan pijat oksitosin sebelum dan sesudah diberi pelatihan pada keluarga pasien ibu nifas di RSUP dr. Soeradji Tirtonegoro Klaten.

Pelatihan pijat oksitosin pada keluarga ibu nifas menunjukkan adanya pengaruh yang positif sesuai dengan teori yang menyatakan bahwa melalui pelatihan seseorang dapat meningkatkan pengetahuan, sikap dan keterampilan, sehingga mampu meningkatkan kompetensi yang diharapkan.

Apabila keluarga ibu nifas dapat melaksanakan pijat oksitosin pada ibu yang habis melahirkan akan sangat bermanfaat untuk meningkatkan produksi ASI sesuai dengan teori yang menyatakan bahwa pijat oksitosin perlu dilakukan untuk merangsang reflek oksitosin sehingga ibu merasa rileks dan tidak kelelahan setelah melahirkan sehingga membantu merangsang pengeluaran hormone oksitosin dan memacu produksi ASI.

\section{PEMBAHASAN}

Berdasarkan hasil penelitian, ada perbedaan ketrampilan pijat oksitosin sebelum dan sesudah diberi pelatihan pada keluarga pasien ibu nifas di RSUP dr. Soeradji Tirtonegoro Klaten. Hasil penelitian yang sama dilakukan Amira Bin Seh Abu Bakar (2008), tentang pengaruh pelatihan manajemen konflik pada kepala ruangan terhadap kinerja perawat pelaksana di ruang rawat inap Rumah Sakit dr. H. Marzoeki Mahdi Bogor dengan hasil penelitian menunjukkan peningkatan yang bermakna pada kinerja perawat pelaksana sesudah dibimbing kepala ruangan yang telah dilatih dan dibimbing ( $p$ value $\leq 0,05$ ).

Suradi \& Tobing (2004), menyatakan bahwa pijat oksitosin perlu dilakukan untuk merangsang reflek oksitosin sehingga ibu merasa rileks dan tidak kelelahan setelah melahirkan sehingga membantu merangsang pengeluaran hormon oksitosin dan memacu produksi ASI.

\section{KESIMPULAN DAN SARAN}

Terdapat perbedaan ketrampilan pijat oksitosin sebelum dan sesudah diberi pelatihan pada keluarga ibu nifas di RSUP dr. Soeradji Tirtonegoro Klaten atau dengan kata lain pelatihan memiliki pengaruh positif untuk meningkatkan ketrampilan pijat oksitosin pada keluarga ibu nifas di RSUP dr. Soeradji Tirtonegoro Klaten.

\section{DAFTAR RUJUKAN}

Biarncuzzo, M. 2002. Breastfeeding the newborn : Clinical strategies for nurses. St. Louis: Mosby 
Bobak, Lowdermilk, \& Jensen. 2004. Buku Ajar Keperawatan Maternitas (Maria A. Wijayarini \& Peter I. Anugerah, Penerjemah). Jakarta : EGC.

Chumbley, Jane. 2003. Menyusui : Panduan para ibu untuk menyusui dan mengenalkan bayi pada susu botol. Jakarta : Erlangga.

Depkes RI. 2007. Pelatihan Konseling Menyusui. Jakarta : EGC.

Manuaba. 2007. Pengantar kuliah obstetri. Cetakan-1. Jakarta:EGC

Moekijat. 1993. Pengembangan dan Motivasi. Bandung : Pionir Jaya

Roesli, U. 2005. Mengenal ASI eksklusif. Jakarta : Trubus Agriwidya.

Rumah Sakit dr. Soeradji Tirtonegoro. 2012. Standar Prosedur Operasional Pijat Oksitosin. Klaten : Rumah Sakit dr. Soeradji Tirtonegoro.

Siagian, S.P. 2009. Manajemen sumber daya manusia. Jakarta: PT Bumi Aksara.

Suherni, Hesty \& Anita. 2009. Perawatan Masa Nifas. Yogyakarta : Fitramaya.

Suradi, R, \& Tobing, H. K. P. 2004. Bahan bacaan manajemen laktasi. Jakarta : Perinasia.

World Health Organization. 2009. Breastfeeding Counselling A Training Course. www.who.int/entity/child_adolesc ent_health/documents/pdfs/bc_part icipants_manual.pdf, (diakses tanggal 13 Maret 2013). 